Policy Research Working Paper 4843

\title{
Connecting Lagging and Leading Regions \\ The Role of Labor Mobility
}

\author{
Somik V. Lall \\ Christopher Timmins \\ Shouyue $Y u$
}

The World Bank

Finance Economics and Urban Development Department

Spatial and Local Development Team

February 2009 
Policy Research Working Paper 4843

\begin{abstract}
How can policies improve the welfare of people in economically lagging regions of countries? Should policies help jobs follow people? Or should they enable people to follow jobs? In most countries, market forces have encouraged the geographic concentration of people and economic activities-policies that try to offset these forces to encourage balanced economic growth have largely been unsuccessful. However, policies that help people get closer to economic density have improved individual welfare. In this paper, the authors examine the migration decisions of working-age Brazilians and find that the pull of higher wages in leading regions has a strong influence on the decision to migrate. However,
\end{abstract}

many people are also "pushed" to migrate, starved of access to basic public services such as clean water and sanitation in their hometowns. Although migration is welfare-improving for these individuals, the economy may end up worse off as these migrants are more likely to add to congestion costs in cities than to contribute to agglomeration benefits. Encouraging human capital formation can stimulate labor mobility for economic gain; and improving access to and quality of basic services in lagging regions will directly improve welfare as well as reduce the type of migration motivated by the search for life-supporting basic services.

This paper-a product of the Spatial and Local Development Team, Finance Economics and Urban Development Department-is part of a larger effort in the department to examine how policies can help integrate lagging and leading regions of countries. Policy Research Working Papers are also posted on the Web at http://econ.worldbank.org. The authors may be contacted at slall1@worldbank.org (Lall) and timmins@econ.duke.edu (Timmins).

The Policy Research Working Paper Series disseminates the findings of work in progress to encourage the exchange of ideas about development issues. An objective of the series is to get the findings out quickly, even if the presentations are less than fully polished. The papers carry the names of the authors and should be cited accordingly. The findings, interpretations, and conclusions expressed in this paper are entirely those of the authors. They do not necessarily represent the views of the International Bank for Reconstruction and Development/World Bank and its affiliated organizations, or those of the Executive Directors of the World Bank or the governments they represent. 


\title{
Connecting Lagging and Leading Regions: The Role of Labor Mobility ${ }^{1}$
}

\author{
Somik V. Lall, Christopher Timmins and Shouyue Yu
}

\footnotetext{
${ }^{1}$ Somik V. Lall (slall1@worldbank.org) is a Senior Economist at the World Bank, Christopher Timmins (timmins@econ.duke.edu) and Shouyue Yu are respectively Associate Professor and Graduate Student at Duke University. The research for this paper has been co-funded by the World Development Report and the Spatial Team in the World Bank. The authors have benefited from discussions and comments from Alex Anas, Jan Brueckner, Gary Burtless, Paul Dorosh, Forhad Shilpi, Antonio Estache, Indermit Gill, Vernon Henderson, Marisela Montoliu, Janet Pack, Truman Packard, Harris Selod, Hyoung Gun Wang, and seminar participants at the World Bank and the BWPUA conference at Brookings.
}

This volume is a product of the staff of the International Bank for Reconstruction and Development/ The World Bank. The findings, interpretations, and conclusions expressed in this paper do not necessarily reflect the views of the Executive Directors of The World Bank or the governments they represent. The World Bank does not guarantee the accuracy of the data included in this work. The boundaries, colors, denominations, and other information shown on any map in this work do not imply any judgment on the part of The World Bank concerning the legal status of any territory or the endorsement or acceptance of such boundaries. 


\section{Motivation and Main Findings}

How can policies improve the welfare of people in economically lagging regions of countries? The answer to this question is not straightforward, and policymakers in developed as well as developing countries struggle in making choices between the market solution of promoting out-migration and the intervention option of promoting economic growth in specific regions. In most countries policy discussions of improving welfare in lagging regions often focus on targeted interventions or "incentives” for moving production to these places. While these efforts are likely to be politically attractive, there is considerable evidence highlighting the limited effectiveness of targeted incentives. And when incentives go against the grain of market forces, they can subtract from rather than add to national economic growth.

At the same time, policymakers have often viewed internal migration - or labor mobility from lagging to leading regions, or rural to urban areas - as a consequence of failed place based policies. And in many countries, policies raise barriers to the movement of labor. Consider the household registration system (the hukou system) in China, which has been a barrier to rural-urban migration. Not having a hukou in urban areas means that migrants do not qualify for public education or health benefits. This can produce large interregional wage differences. Recent research indicates that removing such mobility restrictions would reallocate labor across areas, reduce wage differences, and lower income inequality (Whalley and Zhang 2007).

The World Bank’s World Development Report 2009 (WDR 2009) - Reshaping Economic Geography (World Bank 2008) provides a new framework for territorial development, arguing that policies should focus on integrating lagging and leading regions - and not be exclusively concerned with stimulating growth in lagging regions. The WDR 2009 highlights that enabling geographic mobility of labor and improving economic connectivity between lagging and leading regions are key ingredients for countries to gain from the geographic concentration of economic activities along with convergence in living standards. Which policies can help? Policies that are "spatially blind" in design can have the spatially sharpest effects. These include progressive income tax policies, 
achieving national minimum standards in basic health and education indicators, and removal of barriers to labor mobility. In addition, "spatially connective” policies such as transport and communication improvements physically link lagging and leading regions. "Spatially targeted" incentives should be policy instruments of last resort, only to be used when factor mobility is weak due to internal divisions from ethnic and linguistic fractionalization. In these cases, incentives may be considered, but only after investing in information to identify sources of comparative advantage, and to amplify the benefits from spatially blind and connective policies.

Figure 1 Moving towards economic opportunities: Brazil's young workers move in thousands to get closer to economic density

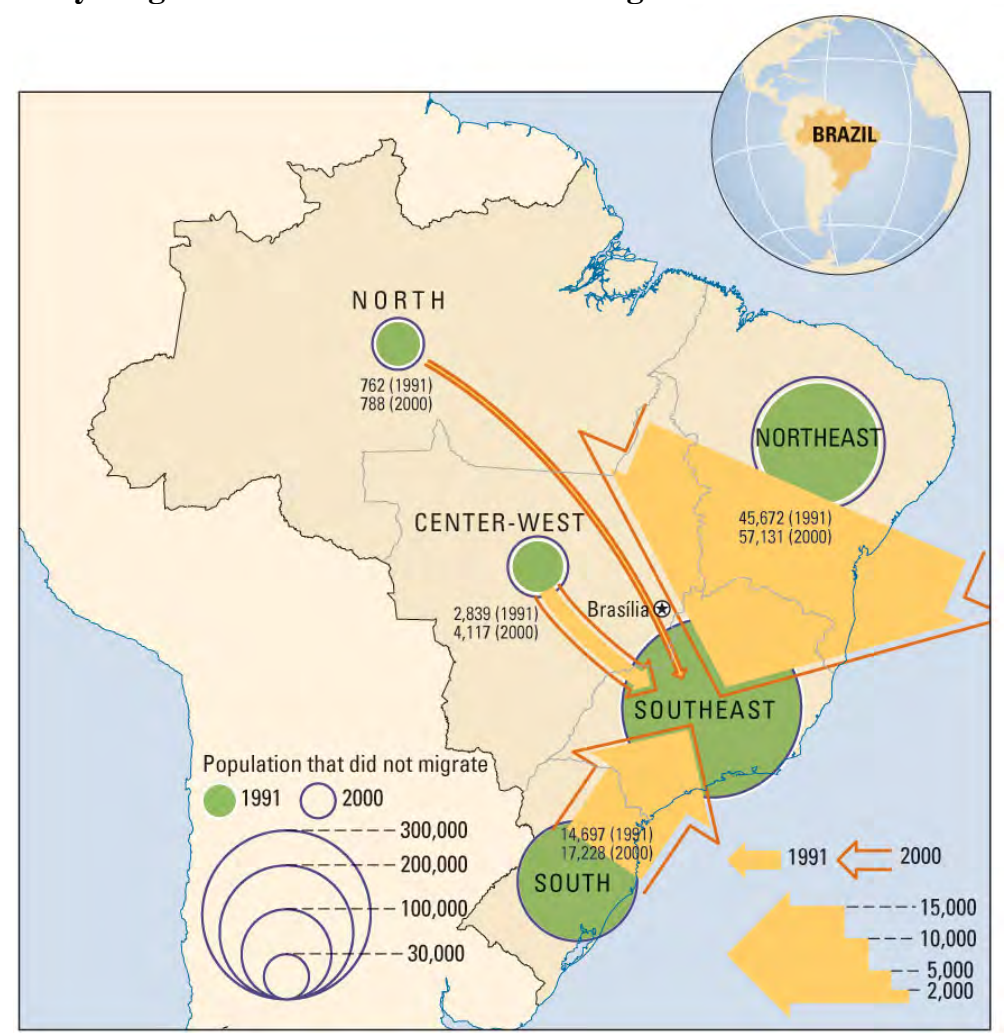

Source: World Bank (2008), based on census data from the Instituto Brasileiro de Geografia e Estatística.

In this paper, we focus on one aspect of the territorial integration challenge - the migration of labor from lagging to leading regions within countries. In particular, we are interested in understanding migration decisions in Brazil - a large developing country with no formal barriers to labor mobility. During years of high economic growth in the 1960s and 1970s, almost 40 million people left the countryside for cities - with a large 
share of those migrants moving from the lagging Northeast to the leading Southeast region (World Bank 2008). And even today, young workers migrate in large numbers (Figure 1 shows migration of 25-35 year old men in 1991 and 2000).

Why people migrate depends on forces that "pull", as well as those that "push" them to leave. One big pull is economic density in leading regions of countries. Differences in economic opportunity between lagging and leading regions often provide the main motivation for internal migration. On the other hand, people are "pushed" off their land where agriculture is in severe decline, by the pressures of population growth and where environmental change makes cultivation no longer viable. Historically, droughts have had sudden and prolonged impact on the distribution of the population, particularly in Sub-Saharan Africa ${ }^{2}$ and South Asia. ${ }^{3}$ Conflict has also pushed people to migrate across Sub-Saharan Africa, and in many other developing regions.

But in many low and middle income countries, another important "push" propels internal migration - the lack of adequate public services in rural areas or in economically lagging regions. To a large extent, this topic has been overlooked in empirical analysis of migration decisions. However in reality, the location of schools, health care centers, hospitals, and public and private amenities is correlated with the location of economic activity. In Africa, disparities in school enrollment and neo-natal care between cities, town and villages are attributable to the near absence of schools and health facilities in outlying areas. ${ }^{4}$ Evidence from Central Asia shows that in the isolated parts of Tajikistan, schools are inadequately heated, drinking water is scarce, and there are no arrangements to clear garbage and sewage. ${ }^{5}$ So as market forces encourage the concentration of economic mass, public services are under-provided in smaller towns, villages, and lagging regions. ${ }^{6}$ Although voluntary, migration in response to limited access to public

\footnotetext{
${ }^{2}$ Iliffe (1995) on the historical impact of drought on population distribution in Africa; Bryceson (1999) on the Sahel and Sudan; and Hardoy and Satterthwaite (1989) on Mauritania.

${ }^{3}$ Wandschneider and Mishra (2003), cited in Deshingkar and Grimm (2004), on the drought-induced migration of 60,000 people out of Bolangir, in the Indian state of Orissa, in 2001.

${ }^{4}$ Sahn and Stifel (2003).

${ }^{5}$ Anderson and Pomfret (2005).

${ }^{6}$ Venables and Kanbur (2005).
} 
services is more likely to add to congestion costs in cities than to contribute to agglomeration benefits.

In the empirical analysis, we examine the relative contribution of economic opportunities and amenities in leading areas (“pull”) and lack of access to basic public services in rural/ lagging regions (“push”) on internal migration decisions of Brazilians. We use household level data that are representative samples down to the second level of sub-national administration (e.g., counties in the United States). These data record migration history over a short-term horizon (e.g., 5 years) and relative to birth location. ${ }^{7}$ Our empirical approach employs repeated cross-sectional data to control for time-invariant unobserved local attributes in a utility-based model of individual migration decisions. Even the best data set will necessarily lack information about important amenities, local public goods, and geo-economic features that might motivate migration behavior. If these unobserved factors are correlated with migration determinants about which we do have information (e.g., access to piped water, sewage, electricity, or healthcare), they can bias our conclusions about the role those observed determinants play in the migration decision. Following Bayer, Keohane and Timmins (2007), we incorporate repeat cross-sectional data on migration behavior into a two-stage discrete choice model that allows us to easily overcome many of these biases, with important implications for our conclusions regarding many of these factors.

Our analysis confirms the importance of public service differentials in influencing longrun migration decisions. In particular, we find that in addition to look for better jobs, working-age men migrated from the lagging Northeast region to get better access to basic public services such as piped water, electricity and health care. How much are migrants willing to pay for public services? A full-time minimum wage worker earning Rs $\$ 7$ per hour (about US\$2.3 in February 2008) was willing to pay Rs\$390 per year in compensating wage differentials to have access to better health services, Rs $\$ 84$ for better access to sewage services, and Rs $\$ 42$ for better access to electricity.

\footnotetext{
${ }^{7}$ We focus on the latter, where missing observations are less of a concern.
} 
What do these findings imply for urbanization and territorial development policies? First, rather than only focusing on providing spatially targeted incentives to stimulate economic growth in lagging regions, policies should focus on building human capital that enables people to become geographically mobile. Second, investing in basic public services and core infrastructure in lagging regions should be of high priority. Access to these services will directly improve welfare in lagging regions, and will reduce the "push" factors that induce migration. By overlooking the provision of basic social services in economically lagging regions, policymakers can inadvertently influence the choice to migrate, motivating households to move for reasons other than to exploit economic opportunities. While the move is welfare-improving for these individuals, the economy may end up worse off as they are more likely to add to congestion costs in cities than to contribute to agglomeration benefits.

The paper proceeds as follows. In Section 2, we discuss the analytic model, which uses a simple model of location choice that depends upon both earning opportunities and local public goods to illustrate that the latter matter in individual migration decisions. In Section 3, we describe the results from estimating the model. Section 4 concludes.

\section{Modeling the Determinants of Migration}

Theories of economic growth and convergence have motivated economic thinking on what causes people to move and what such movements mean. Whether couched in a classical framework ${ }^{8}$ or in the recent models of "endogenous growth," ${ }^{, 9}$ when people are free to move, they will pursue private gain and compete away differences in wages between locations. There is abundant empirical work identifying the determinants of migration decisions, where migrants respond to geographic differences in incomes or wages. In the 1960s and 1970s, aggregate data at the sub national level were used to estimate 'modified gravity models' of migration inspired by Newton's law of gravitation. In these models, migration flows are directly related to population size at the origin and

\footnotetext{
${ }^{8}$ Solow (1956) and Swan (1956).

${ }^{9}$ Romer (1986) and Lucas Jr. (1988).
} 
destination, and inversely related to distance between locations. These gravity models considered the effects of the push and pull factors in both areas of origin and destination. Today, this approach -- which can only broadly describe population movements -- has been replaced by finer micro-econometric methods (Lall, Selod and Shalizi 2007). ${ }^{10}$

The typical migration equation at the micro level specifies a binary variable (moving versus staying) as function of a set of explanatory variables. This approach focuses on the decision to migrate of individuals originally located in a given area. The migration choice can be modeled either with a linear probability, a probit or a logit model. One of the main problems with this approach is that it groups all potential destinations into a single 'rest of the world' destination. This is often due to the lack of available and measurable data, and because multivariate analyses are often less tractable. However, this is an important problem as potential migrants face a set of multiple destinations with different local opportunities. Workers may not only decide whether to migrate but also decide where to migrate, and may be making these choices simultaneously. Without modeling the choice of where to migrate, it is impossible to determine the relative roles of different determinants of migration behavior. An emerging body of empirical analysis addresses this issue by considering polychotomous choice models, usually multinomial logits.

This type of model is used by Falaris (1987) who estimates a nested logit of individual internal migration across 23 states in Venezuela grouped in 7 regions. Distance between states is used as a proxy for moving costs. Consistent with theoretical priors, he finds that wage differentials do indeed affect migration decisions in Venezuela. Our model of migration choice builds on this approach.

\subsection{Model}

We first present a simple model that is geared towards the recovery of the value placed on specific local public services and amenities by potential migrants. The model

\footnotetext{
${ }^{10}$ A discussion on gravity models can be found in Greenwood (1997).
} 
presented there explicitly controls for local public services and amenities, but does so non-parametrically, making it difficult to learn about the value of one in particular (such as access to electricity).

We begin by defining the individual indirect utility function of a potential migrant. As in traditional migration models, we assume that individuals receive utility from wage compensation while trying to avoid higher migration costs (Falaris, 1987). In addition, we assume that individuals enjoy local public goods/amenities such as access to piped water and electricity. Consider an individual $i$ from origin location $j$. We can write his utility, should he choose to reside in location $k$, as:

$$
\tilde{U}_{i, j, k}=\tilde{\beta} w_{i, j, k}-\tilde{\delta} \ln \left(D_{j, k}+0.01\right)+X_{k}^{\prime} \tilde{\gamma}+\tilde{\xi}_{k}+\tilde{\eta}_{i, j, k}
$$

where

$$
\begin{aligned}
w_{i, j, k}= & \log \text { wage earned by individual } i \text { in location } k \\
D_{j, k}= & \text { migration distance (in km from origin } j \text { to location } k \text { ) } \\
X_{k}= & \text { observable (by the econometrician) attributes of location } k \\
\tilde{\xi}_{k}= & \text { unobservable (by the econometrician) attributes of location } k \\
\tilde{\eta}_{i, j, k}= & \text { idiosyncratic unobservable (by the econometrician) determinants } \\
& \text { of individual } i \text { 's utility in location } k
\end{aligned}
$$

For the purpose of easy interpretation, we re-scale equation (2) so that the marginal utility of the natural log of wage is normalized to be one. We remove the “ ” from each parameter to reflect this re-scaling.

$$
U_{i, j, k}=w_{i, j, k}-\delta \ln \left(D_{j, k}+0.01\right)+X_{k}^{\prime} \gamma+\xi_{k}+\eta_{i, j, k}
$$

We can now interpret estimates of $\gamma$ as the marginal willingness-to-pay (as a percentage of wage) for a one-unit increase in any of the attributes in $X_{k}$. 
This model makes a few simplifying assumptions. First, the migration cost is simply related to the migration distance. This is typical of previous analyses, but the model could be extended to treat migration cost as a function of the difference between origin and destination attributes. Second, we do not model the individual's labor market participation decision (i.e., the individual's choice of working hours). Moreover, we also ignore the possibility of involuntary unemployment, but plan to account for this possibility in future work by including unemployment rates in $X_{k} \cdot{ }^{11}$ This is in line with the Harris-Todaro model's emphasis on expected labor market returns.

Suppose there are K locations and individual $i$ can choose one of them as his destination. He will then choose the utility maximizing location. If we assume that $\eta_{i, j, k} \sim$ i.i.d. Type I Extreme Value, the probability that individual $i$ to chooses a particular location $k$ as his destination can be written as:

$$
P\left(U_{i, j, k} \geq U_{i, j, l} \forall l \neq k\right)=\frac{\exp \left(\mu\left(w_{i, j, k}-\delta \log \left(D_{j, k}+0.01\right)+X_{k}^{\prime} \gamma+\xi_{k}\right)\right)}{\sum_{l=1}^{K} \exp \left(\mu\left(w_{i, j, l}-\delta \log \left(D_{j, l}+0.01\right)+X_{l}^{\prime} \gamma+\xi_{l}\right)\right)}
$$

Since the marginal utility of log wage has been rescaled to be one, the model dictates that we explicitly estimate the logit scale parameter, $\mu$. Let $\mathrm{N}$ denote the total population. We would like to maximize the probability associated with the chosen destination of each individual $\left(k_{i}^{*}\right)$. This implies the following log-likelihood function, where $I\left(k=k_{i}^{*}\right)$ is an indicator function that takes the value 1 if individual $i$ chooses location $k_{i}^{*}$ :

$$
\ell=\sum_{i=1}^{N} \sum_{k=1}^{K} \ln \left[P\left(U_{i, j, k} \geq U_{i, j, l} \forall l \neq k\right)\right] * I\left(k=k_{i}^{*}\right)
$$

Using equation (3), the model predicts that the population of location $k$ would be:

\footnotetext{
${ }^{11}$ One could also make the distinction between formal and informal employment
} 


$$
\text { pôp } p_{k}=\sum_{i=1}^{N} P\left(U_{i, j, k} \geq U_{i, j, l} \forall l \neq k\right)
$$

which, in equilibrium, should be equal to the observed population of location $k\left(\operatorname{pop}_{k}\right)$. This applies to all K locations. That is, in equilibrium:

$$
\text { pôp } p_{k}=\operatorname{pop}_{k}, \quad \forall k=1, \cdots, K
$$

We use this information in order to employ the two-stage estimation procedure in Bayer and Timmins (2007). In the first stage, we define the "mean utility" (i.e., separate from idiosyncratic components) enjoyed by all migrants who choose location $k$ :

$$
\theta_{k}=X_{k}^{\prime} \gamma+\xi_{k}
$$

and obtain estimates of $\mu, \delta$ and $\left\{\theta_{k}\right\}_{k=1}^{K}$. Bayer and Timmins (2007) show how, based on equation (6), the contraction mapping formulated in Berry, Levinson, and Pakes (1995) and Berry (1994) can be used to simply calculate the vector $\left\{\hat{\theta}_{k}\right\}_{k=1}^{K}$ for any guess at remaining utility parameters $[\mu, \delta]$ and an arbitrary normalization (e.g., the average value of $\hat{\theta}_{k}$ is set equal to zero). We can then estimate our parameters $\left\lfloor\mu, \delta,\left\{\theta_{k}\right\}_{k=1}^{K}\right\rfloor$ with a maximum likelihood procedure using the log likelihood function (4).

In the second stage, we decompose the estimates $\left\{\hat{\theta}_{k}\right\}_{k=1}^{K}$ from the first stage according to equation (7). This would yield a vector containing the individual's marginal willingnessto-pay (as a percentage of the wage) for each element of the vector $X_{k}$. Since $\xi_{k}$ and $X_{k}$ are likely correlated with each other (e.g., cities with desirable public goods may be "high quality" in other unobserved dimensions), the simple OLS estimator of $\gamma$ will be biased. Ideally, one might use an instrument for each endogenous component of $X_{k}$. Given the number of potentially endogenous local attributes that might be important to the 
individual's migration decision, however, this solution is not practical. Instead, we deal with this problem by assuming that any correlation between $X_{k}$ and $\xi_{k}$ is only with components of $X$ that do not vary over time (i.e., $\varsigma_{k}$ ).

$$
\theta_{k, t}=X_{k, t}^{\prime} \gamma+\underbrace{\varsigma_{k}+v_{k, t}}_{\xi_{k, t}}
$$

Assuming $E\left[\Delta X_{k} \Delta v_{k}\right]=0$, differencing this expression over time will remove any source of bias. While it is unlikely that this assumption holds perfectly, in practice it is a far better option than simply ignoring the role of correlated unobserved local attributes, and it will likely eliminate much of any potential endogeneity bias.

Practically, we expand the first-stage of the model to include data from two census years, restricting the parameters $[\mu, \delta]$ to remain fixed over that time-period. We then solve for two vectors, $\left\{\hat{\theta}_{k, 1}\right\}_{k=1}^{K}$ and $\left\{\hat{\theta}_{k, 2}\right\}_{k=1}^{K}$ using an extension of the Berry, Levinson, and Pakes (1995) contraction procedure. Finally, the unbiased estimates of $\gamma$ can be obtained by estimating:

$$
\Delta \hat{\theta}_{k}=\Delta X_{k}^{\prime} \gamma+\Delta v_{k}
$$

where

$$
\begin{aligned}
& \Delta \hat{\theta}_{k}=\hat{\theta}_{k, 2}-\hat{\theta}_{k, 1} \\
& \Delta X_{k}=X_{k, 2}-X_{k, 1} \\
& \Delta v_{k}=v_{k, 2}-v_{k, 1}
\end{aligned}
$$

\subsection{Data}


The 1991 and 2000 Brazil censuses provide information on current residence and birth state for most individuals. Therefore, we define migration by an individual's current location relative to his birth state. That is, we use a long-run measure of migration. One could also employ a short-run definition of migration - i.e., relative to where the individual was living 1, 2, or 5 years before, if necessary data are available. We use 3659 AMC's (i.e. minimally comparable areas) as destination locations and 27 states as origin locations. AMCs are similar to counties but are aggregated in some cases to make them comparable over time.

For each census year, we focus our attention on household heads who were between the ages of 25 and 35 years. In this way, it is less likely that the same household head will show up in both the 1991 and 2000 samples. Moreover, by using individuals from this cohort, we focus our attention on first migration decisions - i.e., those made after an individual initially finishes school and/or leaves his parent's home. This move may be accompanied by marriage, the birth of a child, etc. Our goal is to avoid mixing these individuals with older individuals who may be making location decisions based on retirement considerations, or who may have made location decisions many years in the past. Finally, we also control for individual attributes, since amenities and employment opportunities are likely to have different effects on migration behavior for different types of individuals. Given that age has already been restricted to be between 25 and 35 years, we further divide those household heads according to their education level. Household heads with post-secondary education are excluded from the analysis.

The Brazilian censuses also contain information on employment and income. Recall that our current model ignores the possibility that the individual would be unable to find work. We therefore keep only those household heads who were employed. In the 2000 census, over $90 \%$ of all Brazilians between the ages of 25-35 (with less than college education) reported that they were working. Thus, dropping unemployed household heads is not a major problem in this context. For each household head in our sample, we can observe his wage in the destination location where he actually resides. However, in order to 
model his destination location decision, we need to know what he would earn in every other location. Properly recovering these counterfactual wages can be quite difficult. In this part of the paper, we adopt the relatively simple approach of using the average wage earned by conditionally similar individuals in those other locations. Practically, this means that we run a separate log wage regression for each AMC:

$$
w_{i, j, k}=Z_{i}^{\prime} \alpha_{k}+v_{i, j, k}
$$

where $Z_{i}$ is a vector of variables describing individual $i$, including age, sex, education level and occupation dummy variables and $\alpha_{k}$ is a set of wage parameters for location $k$. Table 1 reports summaries of regression procedures to predict counterfactual wages.

We model moving costs as a function of migration distance, which is calculated from the longitude and latitude of the center of the individual's birth state and destination AMC. Except for a log-linear function of migration distance, we may also specify moving costs using a set of distance dummies.

Our primary interest is in the role played by regional differences in local public services on migration decisions. We focus on variables describing (1) local infrastructure (i.e., \% households with access to piped water, sewerage, and electric lights), (2) access to healthcare (i.e., number of hospitals), and (3) network infrastructure (i.e., transportation costs to the state capital and São Paulo). Any list of local attributes would, however, necessarily be incomplete. As described above, we use census data from two years to control non-parametrically for all local attributes that do not vary over time. Table 2 summarizes regional differences in access to public services. Differences in water and sanitation services are quite stark. Access to piped water is 52 percent in the Northeast, compared to 72 percent in the Southeast. In terms of access to sewage facilities, connection rates in the Northeast were 13 percent in 2000 - compared to 58 percent in the Southeast.

\section{Main Findings on Migration Choice}


We find strong evidence that individuals' migration decisions depend on more than just returns in the labor market. Ignoring these non-pecuniary determinants may cause us to overstate the role of wages in driving migration decisions. This can be seen in Tables 3 and 4, which describe the results of the procedure described in Section 2.1 for those with less (i.e., 0-6 years) and more (i.e., 7-12 years) education.

Columns 2-5 of the lower panel of each table describe the results of cross-sectional procedures applied to each census year individually and ignoring moving costs. The likely effects of omitted variable bias are evident in the estimates of the utility parameters on access to piped water and number of hospitals. It is likely that each of these variables (particularly the number of hospitals in an AMC) is correlated with other desirable urban amenities. This has the effect of biasing upward the coefficient on each of these variables for both education groups. Access to electricity has a counterintuitive sign or is insignificant. While access to sewage shows the expected sign for those in the lower education group, it exhibits the counterintuitive sign (although it is insignificant) for the higher education group in 1991. In all, these results appear to be unstable over time and likely reflect omitted variable biases caused by unobserved urban amenities.

Columns 6-7 report the results of a differencing procedure that ignores the costs of migration. While controlling non-parametrically for time-invariant unobservable local attributes, this specification ignores the fact that it may be difficult, for example, for someone born in the Northeast to migrate to locations in the Southeast or South of Brazil. The signs of most of the coefficients correspond to expectations; very few of the parameter estimates are, however, statistically significant (only access to electricity and the number of hospitals for those in the lower education group, and the number of hospitals for those in the higher education group are significant). For both groups, an increasing cost of transporting commodities to São Paulo (a measure of national market connectedness) enters negatively into utility, while the cost of transporting commodities to the nearest state capital (a measure of local market connectedness) enters positively. This latter result is counterintuitive. 
Columns 8-9 report the results of our most complete model. Here, we difference over time and control for migration costs. Doing so, we find that \% Sewage, \# hospitals, and transportation cost to the nearest state capital all enter significantly and with the expected sign into the utility of those with less education, while \% Electric Light and \% Piped Water are only marginally insignificant. This reflects the fact that local public goods are indeed important in this group’s migration decision process. For the more educated group, \# Hospitals and \% Electric Light both enter significantly with the expected sign. For this group, however, transportation cost to the nearest state capital and \% Sewage do not seem to matter. It is likely that this group is not on the margin in terms of its access to sewage services (or piped water, for that matter), so a marginal improvement in access to either of these public goods is not likely to provide much inducement for choosing a particular destination. Increasing access to electricity and hospitals are more likely to be important for this group on the margin.

For both groups, increased transportation cost to São Paulo enters into utility positively and significantly in this specification. This result may initially seem counterintuitive. However, after controlling for access to healthcare and other forms of infrastructure (such as proximity to a state capital), this variable may simply proxy for a low cost of living (a desirable amenity).

We can interpret the coefficients on each variable as the percentage of the individual's wage that he is willing to pay for a one unit increase in each variable. For example, an individual from the $[7,12]$ year education group would be willing to pay $4.17 \%$ of his wage in exchange for an additional hospital in his AMC, while he would be willing to pay $1.15 \%$ of his wage in exchange for an additional percentage point of the population being covered by electric lights. An individual from the lower education group would be willing to pay only $0.3 \%$ of his wage in exchange for another percentage point increase in the population covered by electric lights, but would be willing to pay $0.6 \%$ in exchange for an additional percentage point increase in the population with access to sewage services. Since we use the log wage in the model, it reflects that people with higher 
education pay a smaller percentage of their wage for amenities. But their absolute payment for amenities is higher than people with lower education. And for some amenities, better educated people are not marginal and therefore do not really benefit from an improvement at the margin (e.g., connecting more people up to a sewer line does not likely help a rich person, as he was likely hooked up to the sewer line before -- the less educated person is more likely to benefit from that improvement).

\section{Conclusions}

In this paper, we examine the determinants of internal migration paying particular attention to the role of amenities such as access to health and education services and urban infrastructure in the migration decisions of working age individuals. We use Brazilian census data for the analysis and find that the poor from the country's lagging regions not only migrate in search of better economic outcomes, but are often pushed from their hometowns where they are deprived of access to basic public services such as health care, water supply and electricity.

These findings have important implications for territorial development and urbanization policies in Brazil. First, economic activities in industry and services are concentrated in the country's leading areas, benefiting from internal scale economies as well as positive externalities from agglomeration. In Brazil and elsewhere, fiscal incentives and infrastructure programs that have tried to develop industrial clusters in lagging regions have been largely unsuccessful (World Bank 2008, Lall et al 2005, Carvalho et al 2007, World Bank 2005). However, our results show that people have been leaving lagging regions in search of better economic opportunities - particularly in the leading Southeast. Policies should encourage this mobility of labor, and the best way is to help in improving human capital accumulation in lagging regions. Considerable evidence shows that education is the best instrument for overcoming the barriers of distance. One of the biggest success stories comes from the United States, where rise in the schooling of 
African Americans is believed to have been an important causal factor behind their “Great migration” out of the South (Margo 1988).

The Northeast has the worst education attainment in Brazil - the labor force in the Northeast has 4.6 years of schooling compared with the average of 6.4 years nationwide, and 7.3 years in the Southeast. There are estimates suggesting that average incomes in the Northeast would increase by more than half if the local populace had the same education profile as people in the Southeast (Mont'Alverne et al 2004). And neo classical economic thinking suggests that mobility of labor will contribute to inter regional convergence. Since higher wages at the destination reflect an initial shortage of workers relative to capital — or a large endowment of capital per worker - the arrival of new migrants will slow the accumulation of capital per worker and the growth of wages. In contrast, the accumulation of capital per worker in the places migrants leave will speed up as they go, accelerating wage growth for workers who stay behind. By this mechanism, incomes in different locations are predicted to eventually converge.

Second, improving access to public services in lagging regions should be of high priority. While the geographic concentration of economic activities generates increasing returns and helps accelerate economic growth, public policies can help convergence in access to social services. By overlooking the provision of basic social services in economically lagging regions - such as schools, primary health centers, and even basic public infrastructure-policymakers can inadvertently influence the choice to migrate, motivating households to move for reasons other than to exploit economic opportunities. While the move is welfare-improving for these individuals, the economy may end up worse off as they are more likely to add to congestion costs in cities than to contribute to agglomeration benefits. Also, by improving provision of these services, policymakers can directly improve the welfare of the poor in lagging regions. 


\section{REFERENCES}

Anderson, K., and R. Pomfret. 2005. "Spatial Inequality and Development in Central Asia." In Ravi Kanbur, Anthony J. Venables, and G. Wan, (eds.), Spatial Disparities in Human Development: Perspectives from Asia. Tokyo: United Nations University Press.

Ahn, H. and J.L. Powell (1993). "Semiparametric Estimation of Censored Selection Models with a Nonparametric Selection Mechanism.” Journal of Econometrics. 58:3-29.

Au C. C. and J. V. Henderson (2006). "How Migration Restrictions Limit Agglomeration and Productivity in China.” Journal of Economic Development

Bayer, P. and C. Timmins (2007). "Estimating Equilibrium Models of Sorting Across Locations.” Economic Journal.

Bayer, P., N. Keohane, and C. Timmins (2006). "Migration and Hedonic Valuation: The Case of Air Quality.” NBER Working Paper No. W12106.

Berry S. (1994). "Estimating Discrete Choice Models of Product Differentiation.” RAND Journal of Economics. 25: 242-262.

Borjas, G. (1987). “Self-Selection and the Earnings of Immigrants.” American Economic Review. 77:531-553.

Brockerhoff, M. (1995) Fertility and family planning in African cities: The impact of female migration. Journal of Biosocial Science 27: 347-358.

Bryceson, D. (1999). "Sub-Saharan Africa Betwixt and Between. Rural Livelihood Practices and Policies." Leiden, Netherlands: African Studies Centre Working Paper Series 43.

Carvalho, A. S., S. V. Lall, and C. Timmins. (2008). "Regional Subsidies and Industrial Prospects of Lagging Regions." Washington, DC: World Bank Policy Research Working Paper Series 3843.

Dahl, G. (2001). "Mobility and the Return to Education: Testing a Roy Model with Multiple Markets.” Econometrica. 70(6):2367-2420.

Falaris, E. (1987). “A Nested Logit Migration Model With Selectivity.” International Economic Review. 28:429-43.

Hardoy, J. E., and D. Satterthwaite. (1989). Squatter Citizen: Life in the Urban Third World. London, UK: Earthscan Publications.

Iliffe, J. (1995). Africans- The History of a Continent. Cambridge, UK: Cambridge University Press.

Lall, S. V., H. Selod, and Z. Shalizi. (2006). "Rural-Urban Migration in Developing Countries: A Survey of Theoretical Predictions and Empirical Findings." Washington, DC: World Bank Policy Research Working Paper Series 3915. 
Lucas Jr., R. E. (1988). "On the Mechanics of Economic Development." Journal of Monetary Economics 22(1):3-42.

Margo, R. A. (1988), “Schooling and the Great Migration”, NBER working paper\# 2697

Mont'Alverne, A.J, P.C. Ferreira, and M.A. Salvato (2004) "Regional or educational disparities? A counterfactual exercise.” Department of economics working paper 532, FGV, Brazil. The

Romer, P. M. (1986). "Increasing Returns on Long-Run Growth." Journal of Political Economy 94(5):1002-37.

Sahn, D. E., and D. C. Stifel. (2003). "Urban-Rural Inequality in Living Standards in Africa'." Journal of African Economies 12(4):564-97.

Solow, R.. (1956). "A Contribution to the Theory of Economic Growth." Quarterly Journal of Economics 70(1):65-94

Swan, T. (1956). "Economic Growth and Capital Accumulation." Economic Record 32:334-61.

Timmins, C. (2005). "Estimable Equilibrium Models of Locational Sorting and Their Role in Development Economics.” Journal of Economic Geography. 5:83-100.

Timmins, C. (2007). "If You Can't Take the Heat, Get Out of the Cerrado... Recovering the Equilibrium Amenity Effects of Non-Marginal Climate Change in Brazil.” Journal of Regional Science. 47(1):1-25.

Timmins, C. and J. Murdock (2007). "A Revealed Preference Approach to the Measurement of Congestion in Travel Cost Models." Journal of Environmental Economics and Management. 53:230-249.

Venables, A. J., and R. Kanbur. (2005). Spatial Inequality and Development, Overview of the UNU-WIDER Project. New York, NY: Oxford University Press.

Wandschneider, T., and P. Mishra. (2003). Rural Non-Farm Economy and Livelihood Enhancement. Washington, DC: National Resources Institute.

World Bank (2005) Brazil: Regional Economic Development: (Some) Lessons from Experience. Washington, DC: World Bank.

World Bank. (2008). WDR2009: Reshaping Economic Geography. Oxford University Press. 
Table 1

Summary of Regression Procedures to Predict Counterfactual AMC Wages

\begin{tabular}{|c|c|c|c|c|c|c|}
\hline \multirow[b]{2}{*}{ Variable } & \multicolumn{3}{|c|}{2000} & \multicolumn{3}{|c|}{1991} \\
\hline & $\begin{array}{l}\text { Mean of } \\
\text { Parameter } \\
\text { Estimates }\end{array}$ & $\begin{array}{l}\text { Mean of } \\
\text { Std. Err. }\end{array}$ & $\begin{array}{l}\text { Std. Dev. } \\
\text { Parameter } \\
\text { Estimates }\end{array}$ & $\begin{array}{l}\text { Mean of } \\
\text { Parameter } \\
\text { Estimates }\end{array}$ & $\begin{array}{l}\text { Mean of } \\
\text { Std. Err. }\end{array}$ & $\begin{array}{l}\text { Std. Dev. } \\
\text { Parameter } \\
\text { Estimates }\end{array}$ \\
\hline Age & 0.0155 & 0.0014 & 0.0356 & 0.0109 & 0.0009 & 0.0299 \\
\hline primary education dummy & 0.2131 & 0.1302 & 0.3643 & 0.1336 & 0.0679 & 0.2680 \\
\hline $\begin{array}{l}\text { secondary education } \\
\text { dummy }\end{array}$ & 0.6636 & 0.2198 & 0.5217 & 0.6039 & 0.1783 & 0.5507 \\
\hline female dummy & -0.4100 & 0.1533 & 0.4272 & -0.4374 & 0.1875 & 0.4923 \\
\hline \multicolumn{7}{|l|}{ occupation dummies } \\
\hline 1 & 0.1784 & 0.2679 & 0.6140 & 0.4611 & 0.2874 & 0.6873 \\
\hline 2 & 0.3918 & 0.4337 & 0.9072 & 0.2959 & 0.3367 & 0.6998 \\
\hline 3 & 0.1860 & 0.3247 & 0.7365 & -0.3494 & 0.2332 & 0.5950 \\
\hline 4 & 0.1851 & 0.4341 & 0.8089 & 0.0191 & 0.1440 & 0.4605 \\
\hline 5 & 0.0156 & 0.4112 & 0.7394 & 0.1038 & 0.2568 & 0.5923 \\
\hline 6 & -0.1675 & 0.4092 & 0.7996 & 0.2645 & 0.2987 & 0.6850 \\
\hline 7 & -0.4817 & 0.3900 & 0.7959 & 0.2328 & 0.2886 & 0.6349 \\
\hline 8 & -0.0893 & 0.4021 & 0.7887 & -0.1614 & 0.3107 & 0.6246 \\
\hline 9 & -0.1742 & 0.4039 & 0.7467 & 0.1776 & 0.2549 & 0.5270 \\
\hline 10 & -0.0608 & 0.3799 & 0.7384 & & & \\
\hline Constant & -0.1780 & 1.8395 & 1.3723 & 5.1162 & 1.1139 & 1.1206 \\
\hline
\end{tabular}


Table 2: Regional differences in access to public services

\begin{tabular}{|l|r|r|r|r|r|r|r|r|}
\hline & \multicolumn{2}{|c|}{ \% Water } & \multicolumn{2}{c|}{ \% Light } & \multicolumn{2}{c|}{ \% Sewage } & \multicolumn{2}{l|}{$\begin{array}{l}\text { \# Hospital (per } \\
\text { AMC) }\end{array}$} \\
& 1991 & 2000 & 1991 & 2000 & 1991 & 2000 & 1992 & 2000 \\
\hline & 18.1 & 41.0 & 48.0 & 65.5 & 0.9 & 2.2 & 4.0 & 4.6 \\
\hline North Region & 26.2 & 52.2 & 57.3 & 80.5 & 1.7 & 12.9 & 2.2 & 2.4 \\
\hline $\begin{array}{l}\text { Northeast } \\
\text { Region }\end{array}$ & 56.9 & 72.2 & 85.9 & 95.8 & 43.2 & 57.7 & 2.1 & 2.1 \\
\hline $\begin{array}{l}\text { Southeast } \\
\text { Region }\end{array}$ & 48.9 & 65.4 & 89.8 & 97.0 & 3.5 & 13.4 & 2.4 & 2.3 \\
\hline South Region & 40.1 & 66.5 & 76.3 & 92.6 & 4.1 & 7.8 & 3.7 & 3.9 \\
\hline Midwest Region & & & & & & & & \\
\hline
\end{tabular}


Table 3

Migration Estimation Results

Education $=[0,6]$ Years

\begin{tabular}{|c|c|c|c|c|c|c|c|c|}
\hline \multirow[b]{2}{*}{ Stage \#1 } & \multicolumn{4}{|c|}{$\begin{array}{l}\text { No Moving Costs } \\
\text { Second-Stage Without } \\
\text { Differencing }\end{array}$} & \multicolumn{2}{|c|}{$\begin{array}{l}\text { Second-Stage } \\
\text { Differencing (No } \\
\text { Moving Costs) }\end{array}$} & \multicolumn{2}{|c|}{$\begin{array}{l}\text { Moving Costs and } \\
\text { Second-Stage } \\
\text { Differencing }\end{array}$} \\
\hline & \multicolumn{2}{|c|}{ Est } & \multicolumn{2}{|c|}{ t-stat } & Est & t-stat & Est & t-stat \\
\hline Scale Parameter & \multicolumn{2}{|c|}{0.479} & \multicolumn{2}{|c|}{13.20} & 0.479 & 13.20 & 0.397 & 10.94 \\
\hline Moving Costs12 & & & & & & & -1.757 & -10.87 \\
\hline Log Likelihood & \multicolumn{4}{|c|}{28591.164} & \multicolumn{2}{|c|}{28591.164} & \multicolumn{2}{|c|}{21456.657} \\
\hline & \multicolumn{2}{|c|}{1991} & \multicolumn{2}{|c|}{2000} & \multicolumn{2}{|c|}{$\Delta(1991-2000)$} & \multicolumn{2}{|c|}{$\Delta(1991-2000)$} \\
\hline Stage \#2 & Est & t-stat & Est & t-stat & Est & t-stat & Est & t-stat \\
\hline \% Electric Light & $-1.35 \mathrm{E}-03$ & -0.72 & $-1.47 \mathrm{E}-02$ & -5.46 & $1.12 \mathrm{E}-02$ & 8.61 & $2.89 \mathrm{E}-03$ & 1.52 \\
\hline \% Piped Water & $2.15 \mathrm{E}-02$ & 11.69 & $1.01 \mathrm{E}-02$ & 4.86 & $1.99 \mathrm{E}-03$ & 1.21 & $2.48 \mathrm{E}-03$ & 1.04 \\
\hline \% Sewage & $1.64 \mathrm{E}-03$ & 1.14 & $6.07 \mathrm{E}-03$ & 4.97 & $1.38 \mathrm{E}-03$ & 1.22 & $6.35 \mathrm{E}-03$ & 3.86 \\
\hline \# Hospitals & $1.75 \mathrm{E}-01$ & 31.35 & $1.81 \mathrm{E}-01$ & 33.93 & 4.73E-02 & 5.4 & $2.79 \mathrm{E}-02$ & 2.19 \\
\hline Transportation Cost (SP) & 1.87E-04 & 4.1 & 1.17E-04 & 2.25 & $-7.10 \mathrm{E}-04$ & -7.63 & 1.15E-03 & 8.44 \\
\hline Transportation Cost (SC) & $-3.70 \mathrm{E}-04$ & -3.93 & $-6.00 \mathrm{E}-04$ & -6.35 & 6.83E-04 & 2.15 & $-9.60 \mathrm{E}-04$ & -2.06 \\
\hline Constant & $-1.25 \mathrm{E}+00$ & -6.27 & 5.11E-01 & 1.87 & $-2.93 \mathrm{E}-01$ & -8.3 & $-4.53 \mathrm{E}-02$ & -0.88 \\
\hline R2 & \multicolumn{2}{|c|}{0.3522} & \multicolumn{2}{|c|}{0.3215} & \multicolumn{2}{|c|}{0.0886} & \multicolumn{2}{|c|}{0.0418} \\
\hline
\end{tabular}

\footnotetext{
${ }^{12}$ Moving costs are measured as the natural log of the number of kilometers (in 1,000's) from the AMC of residence to the center of the individual's birth state.
} 
Table 4

Migration Estimation Results

Education $=[7,12]$ Years

\begin{tabular}{|c|c|c|c|c|c|c|c|c|}
\hline \multirow[b]{2}{*}{ Stage \#1 } & \multicolumn{4}{|c|}{$\begin{array}{l}\text { No Moving Costs } \\
\text { Second-Stage Without } \\
\text { Differencing }\end{array}$} & \multicolumn{2}{|c|}{$\begin{array}{c}\text { Second-Stage } \\
\text { Differencing (No } \\
\text { Moving Costs) }\end{array}$} & \multicolumn{2}{|c|}{$\begin{array}{l}\text { Moving Costs and } \\
\text { Second-Stage } \\
\text { Differencing }\end{array}$} \\
\hline & \multicolumn{2}{|c|}{ Est } & \multicolumn{2}{|c|}{ t-stat } & Est & t-stat & Est & t-stat \\
\hline Scale Parameter & \multicolumn{2}{|c|}{0.138} & \multicolumn{2}{|c|}{19.95} & 0.138 & 19.95 & 0.253 & 7.75 \\
\hline Moving Costs13 & & & & & & & -2.598 & $\begin{array}{l}-7.69 \\
\end{array}$ \\
\hline \multirow[t]{2}{*}{ Log Likelihood } & \multicolumn{4}{|c|}{25098.315} & \multicolumn{2}{|c|}{25098.315} & \multicolumn{2}{|c|}{18231.261} \\
\hline & \multicolumn{2}{|c|}{1991} & \multicolumn{2}{|c|}{2000} & \multicolumn{2}{|c|}{$\Delta(1991-2000)$} & \multicolumn{2}{|c|}{$\Delta(1991-2000)$} \\
\hline Stage \#2 & Est & t-stat & Est & t-stat & Est & t-stat & Est & t-stat \\
\hline \% Electric Light & $2.60 \mathrm{E}-03$ & 0.34 & $-4.68 \mathrm{E}-02$ & -4.07 & 3.85E-04 & 0.08 & $1.15 \mathrm{E}-02$ & 3.68 \\
\hline$\%$ Piped Water & 2.02E-01 & 26.74 & $1.68 \mathrm{E}-01$ & 18.92 & $8.73 \mathrm{E}-03$ & 1.48 & $4.52 \mathrm{E}-03$ & 1.15 \\
\hline \% Sewage & $-6.27 \mathrm{E}-03$ & -1.06 & $2.22 \mathrm{E}-02$ & 4.25 & $1.63 \mathrm{E}-03$ & 0.4 & $-3.00 \mathrm{E}-04$ & -0.11 \\
\hline \# Hospitals & 7.17E-01 & 31.17 & 7.41E-01 & 32.55 & 8.29E-02 & 2.64 & 4.17E-02 & 1.99 \\
\hline Transportation Cost (SP) & $1.80 \mathrm{E}-03$ & 9.59 & 1.05E-03 & 4.73 & $-1.57 \mathrm{E}-03$ & -4.69 & $4.12 \mathrm{E}-04$ & 1.84 \\
\hline Transportation Cost (SC) & $-2.16 \mathrm{E}-03$ & -5.59 & $-1.79 \mathrm{E}-03$ & -4.46 & $1.53 \mathrm{E}-03$ & 1.35 & $-9.20 \mathrm{E}-05$ & -0.12 \\
\hline Constant & $-1.35 \mathrm{E}+01$ & -16.47 & $-9.16 \mathrm{E}+00$ & -7.85 & $-3.66 \mathrm{E}-01$ & -2.89 & $-3.03 \mathrm{E}-01$ & -3.59 \\
\hline R2 & \multicolumn{2}{|c|}{0.4209} & \multicolumn{2}{|c|}{0.4917} & \multicolumn{2}{|c|}{0.0153} & \multicolumn{2}{|c|}{0.0088} \\
\hline
\end{tabular}

${ }^{13}$ Moving costs are measured as the natural log of the number of kilometers (in 1,000's) from the AMC of residence to the center of the individual's birth state. 